\title{
Evaluation of Adherence to Drug Treatment in Patients with Rheumatoid Arthritis
}

\author{
Abd El-Azeim Alhefny ${ }^{1}$, Maryam Ahmed Abd El-Rahman ${ }^{1}$, Sameh Abd El-Moteleb ${ }^{1}$, \\ Noha Hussein Shedid ${ }^{1}$, Hossam Moussa Sakr ${ }^{2}$, Rasha Mohamed Hassan ${ }^{1}$ \\ Departments of Internal Medicine, Rheumatology Division ${ }^{1}$, Radiodiagnosis ${ }^{2}$, Ain Shams University; Egypt
}

\begin{abstract}
Objectives: The aim of this study was to measure the frequency of medication adherence in rheumatoid arthritis (RA) patients and to assess factors affecting it, deal with some factors to improve adherence and reevaluate after six months. Methods: A prospective cohort interventional study of 100 patients with RA under treatment fulfilled the American College of Rheumatology / European League against Rheumatism (ACR/EULAR) criteria. All patients subjected to full history taking including socio-demographic data, medication and clinical examination, Assessment of disease activity by DAS28, functional ability by Health Assessment Questionnaire (HAQ) score, pain by Visual Analogue Scale (VAS) scale, adherence to treatment by Compliance Questionnaire of Rheumatology (CQR) and Power Doppler U/S for both metacarophalangeal and wrist joints were done at baseline and after 6 months at the end of the study. Analysis of factors of non-adherence was done at baseline before intervention. Results: The baseline adherence rate (CQR $\geq 80)$ was $37 \%$. The cost of medication $(62 \%)$, non-availability of medication in pharmacy (59\%), lack of belief in the benefit of treatment (38\%) forgetting the medication (37\%) , poor provider-patient relationship (25\%), inadequate follow up (23\%) and polypharmacy (20\%) were the most common causes of non adherence in non adherent patients $(\mathrm{p}<0.05)$. Adherent patients to drug treatment were younger, living inside Cairo, with higher level of education and nonsmoker. Non-adherent patients had longer morning stiffness duration $(\mathrm{p}=0.013)$, more tender joints, higher DAS28 and HAQ scores, higher ESR and CRP titer $(\mathrm{p}<0.001)$ and higher frequency of active synovitis in Doppler ultrasound. They also had significantly more frequency of having medications on their expense $(\mathrm{p}<0.001)$. After 6 months of follow up and trying to correct the causes of non-adherence, the adherence rate increased to $69 \%$ and this associated with improvement in disease activity, functional state and ultrasongraphic findings. Conclusion: Adherence rate to drug treatment in RA patients at baseline was low (37\%). It was associated with higher disease activity, functional disability. Patient education, financial support, good physician-patient relationship and simplification of the prescription were found to improve the patient adherence to treatment and to control disease activity after follow up. [Egypt J Rheumatology \& Clinical Immunology, 2016; 4(1): 81-92]
\end{abstract}

Key Words: Rheumatoid arthritis, adherence, Compliance Questionnaire of Rheumatology.

\section{INTRODUCTION}

Rheumatoid arthritis (RA) is a chronic autoimmune disease, with an estimated global prevalence of $1 \%$, characterized by joint inflammation that commonly leads to irreversible joint damage. The resultant pain and joint damage leads to increasingly limited mobility and reduced quality of life ${ }^{1}$. Goals of therapy include minimizing joint pain and swelling, preventing deformity and radiographic damage, maintaining quality of life, and controlling extra-articular manifestations. Disease modifying antirheumatic drugs (DMARDs) are the mainstay of RA therapy ${ }^{2}$. Disease remission will be achieved only if patients follow prescribed treatment regimens reasonably closely ${ }^{3}$. Adherence to therapy has been defined as the extent to which patient's behavior, with respect to taking medication, corresponds with agreed recommendations from a healthcare provider ${ }^{4}$. Non-adherence is associated with negative consequences like disease flares and increased disability ${ }^{5}$. Despite this, adherence rates to prescribed medication regimes in people with RA are low, varying from 30 to $80 \%$. Therefore, improving adherence to therapy could dramatically improve the efficacy of medical treatments and decrease costs associated with $\mathrm{RA}^{6}$. According to the World Health Organization (WHO), factors associated with non-adherence can be divided into five domains: socioeconomic factors; healthcare system factors; condition-related factors; therapy-related factors; and patient-related factors ${ }^{(4)}$. To improve adherence among RA patients, barriers should be identified and appropriate interventions tailored. Strategies targeting the patient, provider and external determinants of adherence may be used to increase medication adherence ${ }^{6}$.

The aim of this study was to measure the frequency of medication adherence in RA patients and to assess factors affecting it, deal with some factors to improve adherence and reevaluate after six months. 


\section{PATIENTS AND METHOD}

This prospective cohort interventional study included one hundred patients with RA under treatment, classified according to the American College of Rheumatology / European League Against Rheumatism (ACR/ EULAR) criteria ${ }^{(7)}$. They were selected from the Outpatient Rheumatology Clinic at Ain Shams University Hospitals between December 2013 and June 2015. It included 80 females and 20 males. Their ages ranged from 21 to 58 years (mean age was $34.58 \pm 8.86$ years) and disease duration ranged from 3 to 8 years (mean disease duration was $5 \pm 2.6$ years). The nature of the present study was explained to all participants. A verbal informed consent was obtained from each patient and after explanation of the study to them. Study protocol gained approval of local ethical committee of Ain Shams University.

At baseline, all patients were subjected to full history taking and clinical examination. Sociodemographics data including age, sex, disease duration, marital status, education, smoking, residence (being inside or outside Cairo), employment and access to medications were assessed. Assessment of disease activity using Disease Activity Score in 28 joints (DAS28) ${ }^{8}$, functional ability using Health Assessment Questionnaire disability index (HAQ-DI) ${ }^{(9)}$ and pain using Visual Analogue Scale (VAS) ${ }^{(10)}$ were done at baseline and after 6 months at the end of the study. DAS28 score was used to stratify disease activity as remission (DAS28 $\leq 2.6$ ), low (DAS28 $>2.6$ and $\leq 3.2$ ), moderate (DAS28 $>3.2$ and $\leq 5.1$ ), or high (DAS28 $>5.1)^{8}$. Measurement of patients' adherence to treatment was done by Compliance Questionnaire of Rheumatology (COR) ${ }^{(11)}$. The CQR is a 19-item rheumatology specific questionnaire assessing medication adherence. The CQR total score can vary from 0 (complete non-compliance) to 100 (perfect compliance). Patients were classified according to this into: group I, non-adherent patients $(\mathrm{CQR}<80 \%)$ and group II, adherent patients (CQR $\geq 80 \%)$. Also the questionnaire contained questions about the reasons that cause non-adherence ${ }^{11}$.

Laboratory investigations including complete blood count (CBC), erythrocyte sedimentation rate (ESR) and C-reactive protein (CRP) titer, were assessed to all patients at baseline and every visit for 1year. Rheumatoid Factor (RF) titer, anti-cyclic citrullinated (anti-CCP) antibodies titer were assessed at baseline only. Power Doppler musculoskeletal ultrasound (MSKUS) for both hands to detect the maximal area of enhancement in the metacarpophalangeal and wrist joints was performed using semi-quantitative technique consisting of a 0-3 scale at baseline and at the end of the study ${ }^{12}$.

Analysis of the data was done at baseline to find out reasons for non-adherence followed by trial of management of some of it through:

- Facilitating the way for getting medications on governmental expense.

- Improving patient doctor relationship and facilitating their communication (e.g. telephone, social media) with increasing trust and changing wrong beliefs.

- Patient (and patients' family if possible) education about RA, its complication, RA medication and its side effects.

- Simplification for the plan of management by decreasing the number of medications as far as possible.

- Monthly monitoring patient adherence to overcome the inadequacy of the follow up (Telephone was used when patients couldn't tolerate this frequency). Follow up of the patients for 6 months and reevaluation of patients' adherence to treatment was studied by the same tools at the end of the study.

\section{Statistical Analysis}

The baseline and follow up data were collected, tabulated and statistically analyzed. Analysis of data was done by personal computer using SPSS (Statistical program for social science) under windows version 17 as follows: description of quantitative variables as mean, standard deviation (SD) and range, description of qualitative variables as number $(\mathrm{N})$ and percentage. Chi-square test was used to compare qualitative variables. Unpaired t-test was used to compare two independent groups as regard a quantitative variables and paired t-test was used to compare groups before and after follow up. Pearson correlation co-efficient rank test was used to rank different variables against each other positively or inversely. P-value $<0.05$ was considered significant and $\mathrm{P} \leq 0.001$ was highly significant.

\section{RESULTS}

Baseline adherence of RA patients by Compliance Questionnaire of Rheumatology (CQR) ranged from 25-95 with a mean of $65.8 \pm 19.24$ and only $37 \%$ of the patients were adherent to their prescribed treatment which is shown in Table (1). The 
most common cause of non-adherence in all RA patients was the cost of medication being detected nearly in half of the patients followed by side effects of medication (41\%) and non availability of medications at hospital pharmacy (Table 2). Comparison between both adherent and non-adherent RA patients regarding reasons for non-adherence showed that non-adherent patients reported significantly higher frequencies of most reasons in comparison to adherent patients (Table 2, Figure 1). The non-adherent patients had significantly more frequency of having medications on their expense (Table 3).

Comparison between both adherent and nonadherent RA patients regarding their sociodemographic and clinical characteristics at baseline is shown in Table 4 and 5. Adherent patients were younger, living inside Cairo, with higher level of education and nonsmoker. Regarding the clinical data, non-adherent patients had longer morning stiffness duration $(\mathrm{p}=0.013)$, more tender joints $(\mathrm{p}=0.001)$, higher frequency of moderate and severe disease activity, higher DAS and HAQ scores $(p=0.001)$. While there was no significant difference regarding disease duration, number of swollen joints, although the number of swollen joints were higher in nonadherent patients. In addition, the non-adherent patients had higher level of ESR and CRP titer $(p=0.001)$ which are markers of disease activity. AntiCCP titer was also significantly higher in nonadherent compared to adherent patients. Regarding MSUS, non-adherent patients had statistically significant higher frequency of moderate grade of vascularity $(p=0.046)$, severe grade of synovial hypertrophy $(\mathrm{p}<0.001)$, moderate grade of effusion $(p=0.025)$ and tendency to have more severe erosion $(\mathrm{p}=0.059)$ compared to adherent patients.
After 6 months of follow up (four patients lost follow up) with our interventions, assessment of adherence of RA patients to treatment by CQR revealed significantly increased frequency of adherent patients to become $68.75 \%$ while non-adherent patients' frequency was $31.25 \%(\mathrm{p}<0.001)$ (Figure 2). There was significant reduction in the number of patients who got their medication on their expense after the follow up ( $p=0.047)$, highly statistical significant decrease in number of tender and swollen joint $(\mathrm{p}<0.001)$ and statistically significant improvement in duration of morning stiffness $(\mathrm{p}=0.025)$, increased frequency of patients in remission and low disease activity $(\mathrm{p}<0.001)$, decreased frequency of patients with moderate $(\mathrm{p}=0.025)$ and severe disease activity $(\mathrm{p}<0.001)$, improvement in mean VAS, HAQ and DAS28 score $(p<0.001)$, decrease in ESR and CRP titer $(p<0.001)$ (Tables 7 and 8). MSUS after follow up is shown in Table (9). RA patients had significant decrease in frequency of effusion, synovial hypertrophy and vascularity with their different grades. Concerning erosions, there was statistically increased in frequency of patients with mild erosions [30 (31.3\%)]. $24(80 \%)$ non-adherent patients in comparison to $6(9.1 \%)$ adherent patients after follow up had these erosions ( $\mathrm{p}$ $<0.001)$ and all the $60(90.9 \%)$ patients with no erosions after follow up were adherent to treatment $(\mathrm{p}<0.001)$.

There were statistically significant negative correlations between $\mathrm{CQR}$ and DAS28 before and after follow up $(\mathrm{p}<0.001)$ and between $\mathrm{CQR}$ and HAQ, VAS scores, ESR and CRP after follow up (Table 10).

Table 1. Treatment of all RA patients.

\begin{tabular}{llll}
\hline & Treatment & N & \% \\
\hline Prednisolon & 81 & 81 \\
Hydroxychloroquine & 72 & 72 \\
Methotrexate & 76 & 76 \\
Lefluonamide & 15 & 15 \\
NSAIDs & 20 & 20 \\
Salphasalazine & 4 & 4 \\
Biologics & 0 & 0 \\
\hline
\end{tabular}

Egypt J Rheumatology and Clinical Immunology | Jan 2016 | Vol. 4 | Issue 1 
Table 2. Reasons for patients' non-adherence to medications at baseline.

\begin{tabular}{lcccccc}
\hline & \multicolumn{2}{c}{$\begin{array}{c}\text { Total } \\
\text { (N=100) }\end{array}$} & $\begin{array}{c}\text { Group I } \\
\text { (non-adherent) } \\
\text { (N=63) }\end{array}$ & $\begin{array}{c}\text { Group II } \\
\text { (Adherent) } \\
\text { (N=37) }\end{array}$ & P-value \\
\cline { 2 - 6 } & $\mathbf{\%}$ & $\mathbf{N}$ & $\mathbf{\%}$ & $\mathbf{N}$ & $\mathbf{\%}$ & \\
\hline 1. Cost of medication & 49 & 39 & 61.9 & 10 & 27.0 & $<0.001$ \\
2. Side effect of medication & 41 & 26 & 41.3 & 15 & 40.5 & 0.086 \\
3. Medication load (polypharmacy) & 13 & 13 & 20.6 & 0 & 0.0 & 0.001 \\
4. Switching to different brand names. & 13 & 10 & 15.9 & 3 & 8.1 & 0.052 \\
5. Non-availability of medication at Ain Shams Hospital pharmacy & 37 & 37 & 58.7 & 0 & 0.0 & $<0.001$ \\
6. Inadequate follow up & 18 & 15 & 23.8 & 3 & 8.1 & 0.005 \\
7. Poor provider-patient relationship. & 16 & 16 & 25.4 & 0 & 0.0 & $<0.001$ \\
8. Patients' lack of belief in the benefit of treatment. & 24 & 24 & 38.1 & 0 & 0.0 & $<0.001$ \\
9. Patient' lack of knowledge. & 9 & 7 & 11.1 & 2 & 5.4 & 0.096 \\
10. Forgetfulness. & 30 & 23 & 36.5 & 7 & 18.9 & 0.003 \\
11. Inability of patient to access pharmacy & 13 & 13 & 20.6 & 0 & 0.0 & 0.001 \\
\hline
\end{tabular}

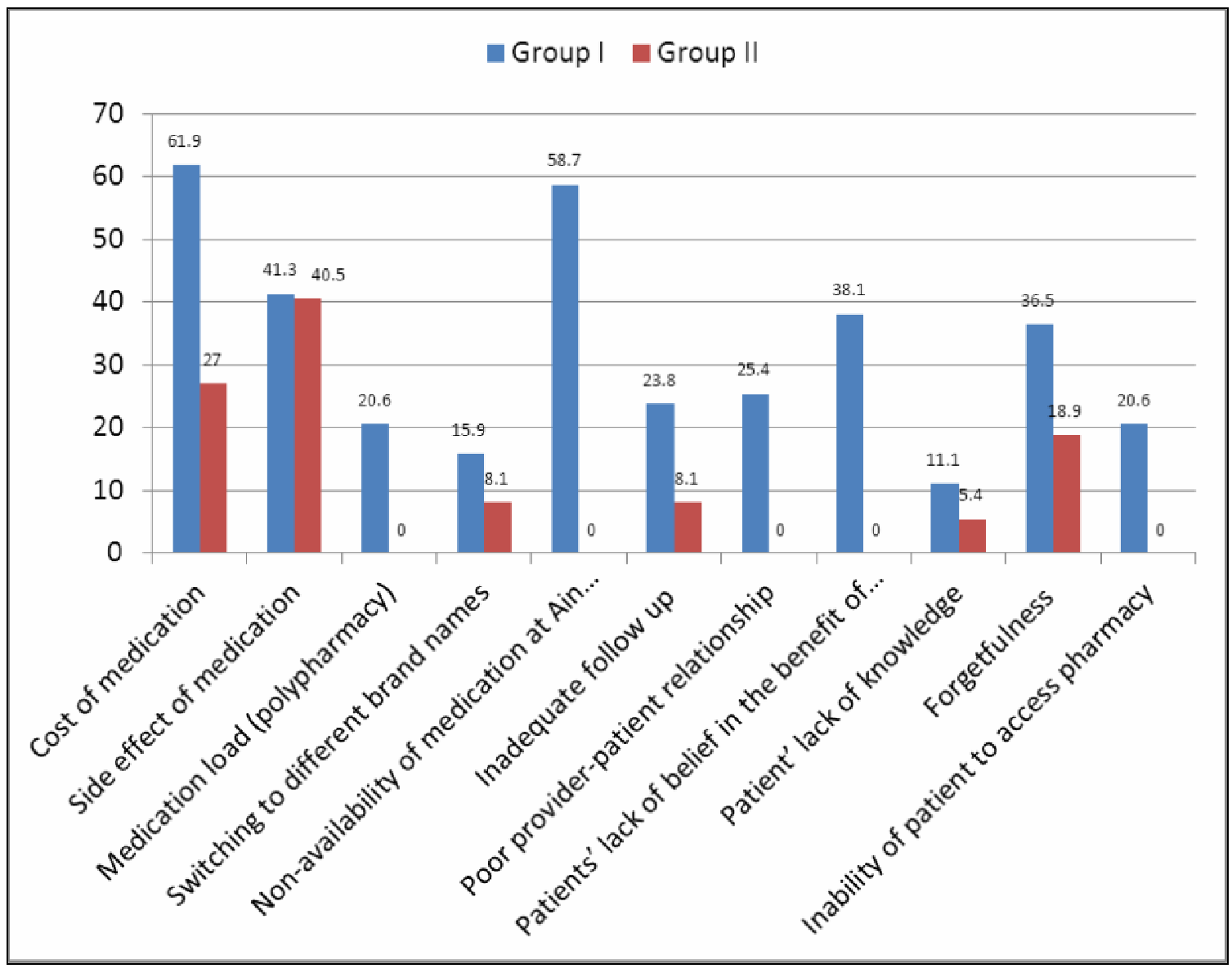

Figure 1. Comparison between adherent and non-adherent patients regarding reasons for non-adherence. 
Table 3. Access to medications in all RA Patients at baseline.

\begin{tabular}{|c|c|c|c|c|c|c|}
\hline \multirow[t]{2}{*}{ Access to medications } & \multirow{2}{*}{$\begin{array}{c}\begin{array}{c}\text { Total } \\
(\mathbf{N}=100)\end{array} \\
\%\end{array}$} & \multicolumn{2}{|c|}{$\begin{array}{c}\text { Group I } \\
\text { (Non-adherent) } \\
(\mathrm{N}=63) \\
\end{array}$} & \multicolumn{2}{|c|}{$\begin{array}{c}\text { Group II } \\
\text { (Adherent) } \\
(\mathrm{N}=37)\end{array}$} & \multirow[t]{2}{*}{ P-value } \\
\hline & & $\mathbf{N}$ & $\%$ & $\mathbf{N}$ & $\%$ & \\
\hline On governmental expense & 54 & 24 & 38.1 & 30 & 81.1 & 0.414 \\
\hline Health insurance & 16 & 11 & 17.5 & 5 & 13.5 & 0.134 \\
\hline On patients' expense & 28 & 26 & 41.3 & 2 & 5.4 & $<0.001$ \\
\hline Charitable organization & 2 & 2 & 3.2 & 0 & 0.0 & 0.317 \\
\hline
\end{tabular}

Table 4. Socio-demographic characteristics of the adherent and non-adherent patients at baseline.

\begin{tabular}{|c|c|c|c|c|c|c|}
\hline & \multirow{2}{*}{$\begin{array}{c}\begin{array}{c}\text { Total } \\
(\mathbf{N}=100)\end{array} \\
\%\end{array}$} & \multicolumn{2}{|c|}{$\begin{array}{c}\text { Group I } \\
\text { (Non-adherent) } \\
(\mathbf{N}=63)\end{array}$} & \multicolumn{2}{|c|}{$\begin{array}{c}\text { Group II } \\
\text { (Adherent) } \\
(\mathbf{N}=37)\end{array}$} & \multirow[t]{2}{*}{ P-value } \\
\hline & & $\mathbf{N}$ & $\%$ & $\mathbf{N}$ & $\%$ & \\
\hline \multicolumn{7}{|l|}{ Sex } \\
\hline Female & 80 & 49 & 77.8 & 31 & 83.8 & \multirow{2}{*}{0.468} \\
\hline Male & 20 & 14 & 22.2 & 6 & 16.2 & \\
\hline \multicolumn{7}{|l|}{ Age (years) } \\
\hline$\leq 30$ & 36 & 18 & 28.6 & 18 & 48.7 & 0.044 \\
\hline$>30-49$ & 58 & 43 & 68.3 & 15 & 40.5 & 0.012 \\
\hline$\geq 50$ & 6 & 2 & 3.1 & 4 & 10.8 & 0.267 \\
\hline Mean \pm SD & $34.58 \pm 8.86$ & \multicolumn{2}{|c|}{$38.33 \pm 7.67$} & \multicolumn{2}{|c|}{$33.81 \pm 6.76$} & 0.014 \\
\hline \multicolumn{7}{|l|}{ Residence } \\
\hline Inside Cairo & 70 & 37 & 58.7 & 33 & 89.2 & \multirow{2}{*}{0.001} \\
\hline Outside Cairo & 30 & 26 & 41.3 & 4 & 10.8 & \\
\hline \multicolumn{7}{|l|}{ Special habits } \\
\hline Non Smoker & 92 & 55 & 87.3 & 37 & 100.0 & \multirow{2}{*}{0.024} \\
\hline Smoker & 8 & 8 & 12.7 & 0 & 0.0 & \\
\hline \multicolumn{7}{|l|}{ Occupation } \\
\hline Employed & 18 & 10 & 15.9 & 8 & 21.6 & \multirow{2}{*}{0.651} \\
\hline Unemployed & 82 & 53 & 84.1 & 29 & 78.4 & \\
\hline \multicolumn{7}{|l|}{ Marital state } \\
\hline Married & 82 & 53 & 84.1 & 29 & 78.4 & \multirow{2}{*}{0.651} \\
\hline Unmarried & 18 & 10 & 15.9 & 8 & 21.6 & \\
\hline \multicolumn{7}{|l|}{ Parity } \\
\hline Having no Children & 17 & 11 & 17.5 & 6 & 16.2 & \multirow{2}{*}{0.907} \\
\hline Having children & 83 & 52 & 82.5 & 31 & 83.8 & \\
\hline \multicolumn{7}{|l|}{ Education } \\
\hline Illiterate & 36 & 30 & 47.6 & 6 & 16.2 & $<0.001$ \\
\hline Primary school & 32 & 24 & 38.2 & 8 & 21.6 & 0.003 \\
\hline Secondary school and college graduate & 32 & 9 & 14.2 & 23 & 62.2 & $<0.001$ \\
\hline
\end{tabular}


Table 5. Clinical and laboratory characteristics of the adherent and non-adherent patients at baseline.

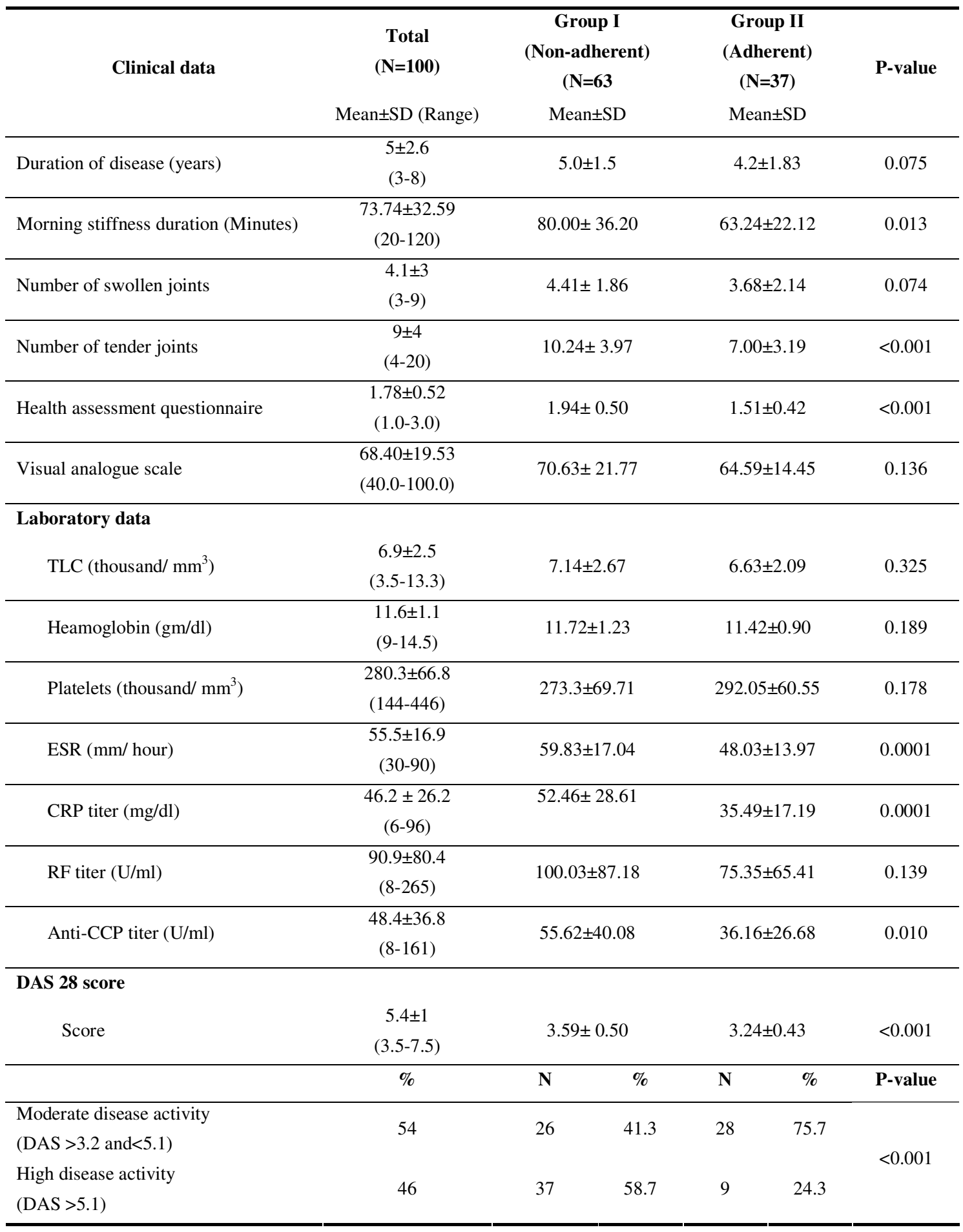


Table 6. Semiquantative Doppler musculoskeletal ultrasound grading of the adherent and non adherent patients at baseline.

\begin{tabular}{|c|c|c|c|c|c|c|}
\hline \multirow[t]{2}{*}{ Doppler MSUS grading } & \multirow{2}{*}{$\begin{array}{c}\begin{array}{c}\text { Total } \\
(\mathbf{N}=100)\end{array} \\
\%\end{array}$} & \multicolumn{2}{|c|}{$\begin{array}{c}\text { Group I } \\
\text { (Non-adherent) } \\
(\mathbf{N}=63) \\
\end{array}$} & \multicolumn{2}{|c|}{$\begin{array}{c}\text { Group II } \\
\text { (Adherent) } \\
(\mathrm{N}=37) \\
\end{array}$} & \multirow[t]{2}{*}{ P-value } \\
\hline & & $\mathbf{N}$ & $\%$ & $\mathbf{N}$ & $\%$ & \\
\hline \multicolumn{7}{|l|}{ Vascularity } \\
\hline No $(0)$ & 40 & 22 & 34.9 & 18 & 48.6 & 0.527 \\
\hline Grade $1=$ Mild & 40 & 25 & 39.7 & 15 & 40.5 & 0.114 \\
\hline Grade $2=$ Moderate & 16 & 12 & 19.0 & 4 & 10.8 & 0.046 \\
\hline Grade $3=$ Severe & 4 & 4 & 6.3 & 0 & 0.0 & 0.102 \\
\hline \multicolumn{7}{|l|}{ Synovial hypertrophy } \\
\hline Grade 1 & 24 & 11 & 17.5 & 13 & 35.1 & 0.081 \\
\hline Grade 2 & 53 & 30 & 47.6 & 23 & 62.2 & 0.228 \\
\hline Grade 3 & 23 & 22 & 34.9 & 1 & 2.7 & $<0.001$ \\
\hline \multicolumn{7}{|l|}{ Effusion } \\
\hline No & 43 & 24 & 38.1 & 19 & 51.4 & 0.446 \\
\hline Grade 1 & 33 & 20 & 31.7 & 13 & 35.1 & 0.223 \\
\hline Grade 2 & 20 & 15 & 23.8 & 5 & 13.5 & 0.025 \\
\hline Grade 3 & 4 & 4 & 6.3 & 0 & 0.0 & 0.102 \\
\hline \multicolumn{7}{|l|}{ Erosion } \\
\hline No & 83 & 51 & 83.6 & 32 & 86.5 & 0.431 \\
\hline Grade 1 & 7 & 3 & 4.9 & 4 & 10.8 & 0.705 \\
\hline Grade 2 & 3 & 2 & 3.3 & 1 & 2.7 & 0.564 \\
\hline Grade 3 & 5 & 5 & 8.2 & 0 & 0.0 & 0.059 \\
\hline
\end{tabular}

Table 7. Access to medications in all RA Patients at baseline and after follow up.

\begin{tabular}{|c|c|c|c|c|c|}
\hline \multirow{2}{*}{ Access to medications } & \multicolumn{2}{|c|}{$\begin{array}{l}\text { Baseline } \\
(\mathrm{N}=100)\end{array}$} & \multicolumn{2}{|c|}{$\begin{array}{c}\text { Follow up } \\
(\mathrm{N}=96)\end{array}$} & \multirow{2}{*}{ P-value } \\
\hline & $\mathbf{N}$ & $\%$ & $\mathbf{N}$ & $\%$ & \\
\hline Treatment on governmental expense & 54 & 54.0 & 69 & 71.8 & 0.091 \\
\hline Health insurance & 16 & 16.0 & 14 & 14.5 & 0.521 \\
\hline On patients' expense & 28 & 28.0 & 13 & 13.5 & 0.047 \\
\hline Charitable organization & 2 & 2.0 & 0 & 0 & 0.414 \\
\hline
\end{tabular}


Table 8. Clinical and laboratory characteristics of the RA patients at baseline and after follow up.

\begin{tabular}{|c|c|c|c|c|c|c|c|}
\hline & & \multirow[b]{2}{*}{ Mean } & \multirow[b]{2}{*}{ SD } & \multicolumn{2}{|c|}{ Paired Difference } & \multicolumn{2}{|c|}{ Paired Difference t-test } \\
\hline & & & & Mean & SD & $\mathrm{t}$ & p-value \\
\hline \multirow{2}{*}{ Number of swollen joints } & Basal & 4.17 & 2.00 & \multirow{2}{*}{3.46} & \multirow{2}{*}{2.14} & \multirow{2}{*}{15.82} & \multirow{2}{*}{$<0.001$} \\
\hline & Follow up & 0.71 & 1.25 & & & & \\
\hline \multirow{2}{*}{ Number of tender joints } & Basal & 9.04 & 4.01 & \multirow{2}{*}{7.31} & \multirow{2}{*}{3.55} & \multirow{2}{*}{20.19} & \multirow{2}{*}{$<0.001$} \\
\hline & Follow up & 1.73 & 2.19 & & & & \\
\hline \multirow{2}{*}{$\begin{array}{l}\text { Morning stiffness duration } \\
\text { (Min.) }\end{array}$} & Basal & 90.36 & 36.23 & \multirow{2}{*}{17.32} & \multirow{2}{*}{38.60} & \multirow{2}{*}{2.37} & \multirow{2}{*}{0.025} \\
\hline & Follow up & 73.04 & 29.76 & & & & \\
\hline \multirow{2}{*}{ Visual analogue scale } & Basal & 68.75 & 19.75 & \multirow{2}{*}{31.25} & \multirow{2}{*}{20.38} & \multirow{2}{*}{15.03} & \multirow{2}{*}{$<0.001$} \\
\hline & Follow up & 37.50 & 13.99 & & & & \\
\hline \multirow{2}{*}{$\begin{array}{l}\text { Health assessment } \\
\text { questionnaire }\end{array}$} & Basal & 1.77 & 0.53 & \multirow{2}{*}{0.59} & \multirow{2}{*}{0.58} & \multirow{2}{*}{9.99} & $<0001$ \\
\hline & Follow up & 1.18 & 0.44 & & & & \\
\hline Laboratory data & & & & & & & \\
\hline DAS & Basal & 5.4 & 1.0 & 23 & 12 & 1240 & $<0.001$ \\
\hline S & Follow up & 3.1 & 0.9 & 2.0 & 1.0 & 12. & \\
\hline TI $C$ & Basal & 6.96 & 2.47 & 028 & 377 & 073 & 0.465 \\
\hline 10 & Follow up & 7.24 & 2.72 & 0.20 & י & $0.7 \mathrm{~J}$ & \\
\hline & Basal & 11.57 & 1.12 & & & & \\
\hline 10 & Follow up & 11.55 & 1.38 & 0.00 & 1.00 & 0.10 & 0.071 \\
\hline PLT & Basal & 279.79 & 67.84 & 878 & 11113 & 077 & 0441 \\
\hline 101 & Follow up & 271.01 & 77.35 & 0.10 & 11.0 & ד & 0.47 \\
\hline ESP & Basal & 55.65 & 17.13 & 2773 & 1625 & 1672 & 00001 \\
\hline LMT & Follow up & 27.92 & 13.36 & 21.13 & 10.20 & 10.12 & -0.001 \\
\hline$C$ reoctive protein & Basal & 45.98 & 26.69 & 3607 & 2708 & 13237 & 00001 \\
\hline & Follow up & 9.01 & 14.13 & & & & \\
\hline DAS & & $\mathrm{N}$ & $\%$ & & & & \\
\hline Remission $(\leq 2.6)$ & Basal & 0 & 0.0 & & & 001 & \\
\hline & Follow up & 29 & 30.2 & & & & \\
\hline Low disease activity & Basal & 0 & 0.0 & & & 001 & \\
\hline$(>2.6$ and $\leq 3.2)$ & Follow up & 28 & 29.2 & & & & \\
\hline Moderate disease activity & Basal & 54 & 54.0 & & & 025 & \\
\hline$(>3.2$ and $\leq 5.1)$ & Follow up & 36 & 37.5 & & & & \\
\hline High disease activity & Basal & 46 & 46.0 & & & .001 & \\
\hline$(>5.1)$ & Follow up & 3 & 3.1 & & & & \\
\hline
\end{tabular}


Alhefny, et al.: Adherence to Drug Treatment in Patients with Rheumatoid Arthritis

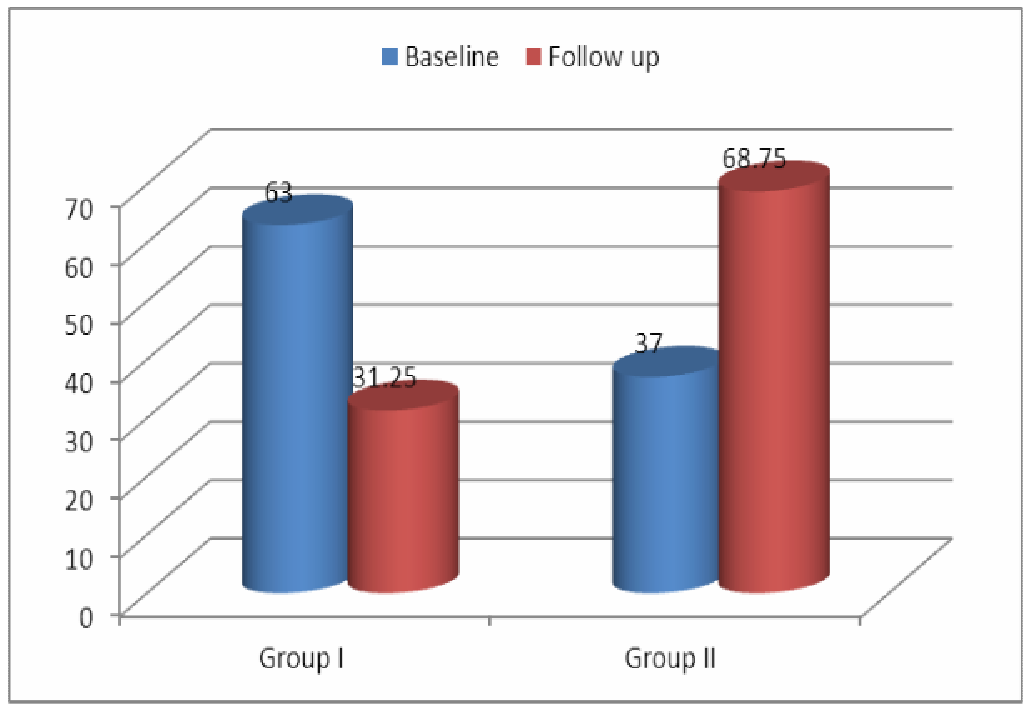

Figure 2. Frequency of adherence at baseline and after follow up.

Table 9. Semiquantative Doppler musculoskeletal ultrasound grading patients at baseline and after follow up.

\begin{tabular}{|c|c|c|c|}
\hline \multirow{2}{*}{ MSUS } & Baseline $(\mathrm{No}=100)$ & Follow up $(\mathrm{No}=96)$ & \multirow{2}{*}{ P-value } \\
\hline & $\mathbf{N}(\%)$ & $\mathbf{N}(\%)$ & \\
\hline \multicolumn{4}{|l|}{ Vascularity } \\
\hline No $(0)$ & $40(40 \%)$ & $72(75 \%)$ & $<0.001$ \\
\hline Grade 1= Mild & $40(40 \%)$ & $20(20.8 \%)$ & 0.006 \\
\hline Grade $2=$ Moderate & $16(16 \%)$ & $4(4.2 \%)$ & 0.013 \\
\hline Grade $3=$ Severe & $4(4 \%)$ & $0(0 \%)$ & 0.14 \\
\hline \multicolumn{4}{|l|}{ Synovial hypertrophy } \\
\hline Grade 1 & $24(24 \%)$ & $66(68.75 \%)$ & $<0.001$ \\
\hline Grade 2 & $53(53 \%)$ & $22(22.92 \%)$ & $<0.001$ \\
\hline Grade 3 & $23(23 \%)$ & $8(8.33 \%)$ & 0.009 \\
\hline \multicolumn{4}{|l|}{ Effusion } \\
\hline Grade 0 & $43(43 \%)$ & $68(70.83 \%)$ & $<0.001$ \\
\hline Grade 1 & $33(33 \%)$ & $26(27.08 \%)$ & 0.455 \\
\hline Grade 2 & $20(20 \%)$ & $2(2.08)$ & $<0.001$ \\
\hline Grade 3 & $4(4 \%)$ & $0(0 \%)$ & \\
\hline \multicolumn{4}{|l|}{ Erosion } \\
\hline Grade 0 & $83(83 \%)$ & $60(62.5 \%)$ & $<0.001$ \\
\hline Grade 1 & $7(7 \%)$ & $30(31.3 \%)$ & $<0.001$ \\
\hline Grade 2 & $3(3 \%)$ & $4(4.2 \%)$ & 0.671 \\
\hline Grade 3 & $5(5 \%)$ & $2(2.1 \%)$ & 0.949 \\
\hline
\end{tabular}


Table 9. Correlations between $\mathrm{CQR}$ after follow up and other parameters.

\begin{tabular}{lcc}
\hline \multirow{2}{*}{ Follow-up } & \multicolumn{2}{c}{ CQR } \\
\cline { 2 - 3 } & $\mathbf{r}$ & P-value \\
\hline Age & -0.043 & 0.669 \\
Duration of disease & -0.168 & 0.094 \\
DAS28 score & -0.424 & $<0.001$ \\
HAQ & -0.437 & $<0.001$ \\
VAS & -0.270 & 0.007 \\
ESR & -0.404 & $<0.001$ \\
CRP & -0.276 & 0.005 \\
\hline
\end{tabular}

\section{DISCUSSION}

In this study the baseline medication adherence rate in patients with RA as measured by CQR was $37 \%$. Estimates of the extent to which patients adhere to RA therapy varied between $22 \%$ (underuse) and $107 \%$ (overuse). This variation could be attributed to differences in the study groups, the type of drugs included and methods of assessment ${ }^{6}$. Adherence rates in studies using refill dates ranged from 22 to $73 \%^{13-15}$, adherence rates obtained with Medication Events Monitoring System (MEMS) devices ranged from 72 to $107 \%{ }^{16,17}$ and with self report (similar to our study) from 50 to $99 \%$.

While many factors influence drug adherence, the cost of medications and non availability of drugs at hospital pharmacy were the most common in our patients. These patients were selected from Ain Shams University Rheumatology Clinic which nearly offers examination service and medications freely and most of patients are having low economic level. Treatment of chronic disease like RA with multiple drugs for a long time is considered a very big load for them if they don't find it for free at hospital pharmacy especially that most of them don't have medical insurance and have the medications on their expense.

An important factor contributing to nonadherence in patients with RA in this study was the patient's lack of belief in the benefit of treatment. Patients seem to have better adherence when the treatment regimen makes sense to them: when the treatment seems effective, the benefits seem to exceed the risks/costs, and when they feel they have the ability to succeed at the regimen ${ }^{6}$. The negative beliefs about medications are found closely related to nonadherence in many studies concerning $\mathrm{RA}^{20-22}$.

In this study, a poor provider-patient relationship is found significantly associated with non-adherence. This relationship becomes a critical factor in determining a patient's adherence especially in the face of medication costs. A strong relationship means development of greater trust with patient's healthcare provider and this will come with good communication which will contribute to patients' understanding illness and the risks and benefits of treatment ${ }^{20,23}$.

Many socio-demographic factors have been studied as potential risk factors for non-adherence. In this study, Adherent patients were younger, living inside Cairo, with higher level of education and nonsmoker. Age is not consistently associated with medication non-adherence. While some studies reported that older patients had better adherence, others documented that younger patients tends to be more adherers as we found ${ }^{5,17-19}$. Multiple comorbidities and complex medical regimens, which are both often associated with an increased age, may be responsible for non-adherence ${ }^{6}$. A positive association between the level of education and adherence was found by other studies ${ }^{24,25}$, similar to our findings, while van den Bemt et al. found no significant relation between level of education and adherence ${ }^{19}$. Patients with low literacy level may be unaware about potential problems and may have difficulty understanding instructions; this ultimately leads to decreased adherence and poor medication management ${ }^{26}$. While we found that disease duration had no relation to adherence similar to many authors $^{18,20,27,28}$, others found long standing experience of RA may have made the patients more aware of the implications of further flares ${ }^{29}$ and others found that adherence to medications decreases with time ${ }^{16,19}$.

In this study, the non-adherent patients were having more disease activity and worse radiological findings by MSUS. This was in agreement with Waimann et al. who found that patients with better adherence showed less disease activity $^{27}$ and Contreras-Yanez et al. who reported that therapy behavior of patients with RA with mild/no disease activity and disability was poor and translated into disease flares ${ }^{5}$. 
Knowledge of factors associated with medication non-adherence in RA could help health professionals to detect the type of adherence-improving interventions ${ }^{6}$. In the present study, some reasons for non-adherence in the RA patients, which have been discovered at baseline, were tried to be corrected through the follow up period especially the cost of medication by facilitation getting the medication on governmental expense, patient education about the disease, risk and benefit of treatment, simplification of the plan of management, enforcement of the patient-doctor relationship and strict follow up. We tried to tailor effective interventions to meet patient needs rather than offering the same intervention to all patients. The effectiveness of these interventions was translated at the end of the study into improvement of the adherence of the patients from $37 \%$ to become $69 \%$ as measured by CQR. There was improvement of disease activity, functional ability and sonographic findings corresponding to the improvement in adherence. Similar improvement in medication adherence and disease activity was reported by many authors in the intervention group compared with the control group $^{27,30,31}$. This was in contrary to a recent study which tested the effect of a motivational interviewing programme on medication adherence in RA patients and did not demonstrate any significant change to patient beliefs about medications or in improving medication adherence and this may be due to focusing on patient-related factors only ${ }^{32}$. Other interventional studies failed to improve medication adherence were reported $^{33,34}$. Most of this interventions were educational depends on enhancing patient knowledge and understanding of their disease but education alone is insufficient to increase medication adherence. Nonadherence is also caused by other types of factors according to the WHO. In addition, interventions that target adherence are needed to be tailored to patients' needs and reasons for not taking medications ${ }^{6}$. By targeting multiple factors of non-adherence in this study according to patients' reasons, a better medication adherence and better disease control were achieved.

In conclusion, adherence rate to drug treatment in RA patients at baseline was low (37\%). This was associated with higher disease activity, functional disability. Patient education, financial support, good physician-patient relationship and simplification of the prescription were found to improve the patient adherence to treatment and to control disease activity after follow up.

\section{REFERENCES}

1. Dowman B, Campbell R, Zgaga L et al, Estimating the burden of rheumatoid arthritis in Africa: A systematic analysis. Journal of Global Health 2012; $2(2): 1-9$.
2. Wasserman A. Diagnosis and Management of Rheumatoid Arthritis.American Family Physician J. 2011; 84 (11):1245-1252.

3. Harrold LR and Andrade SE. Medication adherence of patients with selected rheumatic conditions: a systematic review of the literature. Semin Arthritis Rheum. 2009; 38 (5): 396-402.

4. World Health Organization. Adherence to longterm Therapies: evidence for action 2003.

Available at: www.who.int/chp/knowledge/publications/adheren ce_full_report.pdf.

5. Contreras-Yáñez I, Ponce De León S, Cabiedes J et al. Inadequate therapy behavior is associated to disease flares in patients with rheumatoid arthritis who have achieved remission with diseasemodifying antirheumatic drugs. Am J Med Sci. 2010; 10: 282-290.

6. van den Bemt BJ, Zwikker HE and van den Ende $\mathrm{CH}$. Medication adherence in patients with rheumatoid arthritis: a critical appraisal of the existing literature Expert Rev. Clin. Immunol. 2012; 8 (4): 337-351.

7. Aletaha D, Neogi T, Silman A et al. Rheumatoid arthritis classification criteria: an American College of Rheumatology/European League against Rheumatism collaborative initiative. Arthritis Rheum. 2010; 62: 2569- 2581.

8. Prevoo ML, Van't Hof MA, Kuper HH et al. Modified disease activity scores that include twenty-eight-joint counts. Development and validation in a prospective longitudinal study of patients with rheumatoid arthritis. Arthritis Rheum.1995; 38: 44-48.

9. Fries JF, Spitz P, Kraines RG et al. Measurement of Patient Outcome in Arthritis. Arthritis and Rheumatism.1980; 23: 137- 145.

10. Huskisson EC. Measurment of pain. J Rheumatol 1982; 9: 768- 9 .

11. De Klerk E, van der Heijde D, Landewé R et al. The Compliance Questionnaire Rheumatology Compared with Electronic Medication Event Monitoring: A Validation Study. The Journal of Rheumatology 2003; 30(11): 2462- 2475.

12. Kurosaka D, Hirai K, Nishioka $M$ et al. , Clinical Significance of Serum Levels of Vascular Endothelial Growth Factor, Angiopoietin-1, and Angiopoietin-2 in Patients with Rheumatoid Arthritis, (2010),37(6):1121-1128.

13. Grijalva CG, Kaltenbach L, Arbogast PG et al. Adherence to disease-modifying antirheumatic drugs and the effects of exposure misclassification on the risk of hospital admission. Arthritis Care Res. 2010; 62(5), 730-734.

14. Borah BJ, Huang X, Zarotsky $\mathrm{V}$ et al. Trends in RA patients' adherence to subcutaneous anti-TNF therapies and costs. Curr. Med. Res. Opin. 2009; 25(6), 1365-1377. 
15. Curkendall $\mathrm{S}$, Patel $\mathrm{V}$, Gleeson $\mathrm{M}$ et al. Compliance with biologic therapies for rheumatoid arthritis: do patient out-of pocket payments matter? Arthritis Rheum. 2008; 59(10), 1519-1526.

16. de Klerk E, van der Heijde D, Landewé $\mathrm{R}$ et al. Patient compliance in rheumatoid arthritis, polymyalgia rheumatica, and gout. J. Rheumatol. 2003; 30, 44-54.

17. Park DC, Hertzog C, Leventhal $\mathrm{H}$ et al. Medication adherence in rheumatoid arthritis patients: older is wiser. J. Am. Geriatr. Soc. 1999; 47, 172-183.

18. Tuncay R, Eksioglu E, Cakir B et al. ,Factors affecting drug treatment compliance in patients with rheumatoid arthritis. Rheumatol Int. 2007; 278: 743-746.

19. van den Bemt BJ, van den Hoogen FH, Benraad B et al., Adherence rates and associations with nonadherence in patients with rheumatoid arthritis using disease modifying antirheumatic drugs.J Rheumatol. 2009; 3610: 2164-2170.

20. Treharne GJ, Lyons AC, Kitas GD. Medication adherence in rheumatoid arthritis: effects of psychological factors. Psychol Health Med 2004; 9: 337- 49.

21. Neame R, Hammond A. Beliefs about medications: a questionnaire survey of people with rheumatoid arthritis. Rheumatology (Oxford) 2005; 44(6), 762767

22. Horne R, Weinman J, Hankins M. The Beliefs about Medicines Questionnaire: the development and evaluation of a new method for assessing the cognitive representation of medication. Psychol Health 1999; 14: 1-24.

23. Zolnierek $\mathrm{K}$ and DiMatteo $\mathrm{M}$. Physician communication and patient adherence to treatment: A Meta-analysis. Med Care 2009; 47(8): 826-834.

24. Santana L, Fontenelle L. A review of studies concerning treatment adherence of patients with anxiety disorders. Patient Preference and Adherence 2011; 5: 427- 439.

25. de Thurah A, Norgaard M, Johansen MB et al. Methotrexate compliance among patients with rheumatoid arthritis: the influence of disease activity, disease duration, and co-morbidity in a 10- year longitudinal study. Scand J Rheumatol. 2010; 393: 197-205.

26. Jimmy B, Jose J. Patient medication adherence: Measures in daily practice: review article. Oman Medical Journal. 2011; 26 (3): 155- 159.

27. Waimann, C, Marengo M, Achaval S et al. Electronic monitoring of oral therapies in ethnically diverse and economically disadvantaged patients with rheumatoid arthritis. Consequences of low adherence. Arthritis Rheum. 2013; 5(6): 1421- 1429.

28. Salt E and Frazier SK. Adherence to diseasemodifying antirheumatic drugs in patients with rheumatoid arthritis: a narrative review of the literature. Orthop Nurs. 2010; 29 (4): 260-275.

29. Morgan C, McBeth J, Cordingley L et al. The influence of behavioural and psychological factors on medication adherence over time in rheumatoid arthritis patients: a study in the biologics era. Rheumatology oxford journal 2015; 4: 1-12.

30. Ravindran V and Jadhav $R$. the effect of rheumatoid arthritis disease education on adherence to medication and follow up in Kerala. J Rheumatol. 2013; 40: 1460- 1471.

31. Hill J, Bird H, and Johnson S. Effect of patient education on adherence to drug treatment for rheumatoid arthritis: a randomised controlled trial. Annals of the Rheumatic Diseases. 2001; 60: 869875.

32. Zwikker HE, van den Ende CH, van Lankveld WG et al. Effectiveness of a group-based intervention to change medication beliefs and improve medication adherence in patients with rheumatoid arthritis: a randomized controlled trial. Patient Education and Counseling 2014; 94: 356- 361.

33. Conn DL, Pan Y, Easley KA et al., The effect of the Arthritis Self-Management Program on outcome in African Americans with rheumatoid arthritis served by a public hospital. Clin Rheumatol, (2013), 32: 49-59.

34. Rudd RE, Blanch DC, Gall Vet al. A randomized controlled trial of an intervention to reduce low literacy barriers in inflammatory arthritis management. Patient Educ Coun. 2009; 75: $334-$ 339. 